\title{
Classification of Books for Libraries in which Readers are allowed Access to the Shelves. ${ }^{1}$
}

$\mathrm{O}$ anyone who has studied the subject of classification with
regard to public requirements, in cases where it has been found desirable to admit readers among the books, the ordinary numerical finding arrangement will present itself as impracticable. By the numefical finding arrangement we mean the plan of numbering a whole great class of literature irrespective of the relationships of sub-sections or individual books. A familiar example is furnished by the class "Arts and Sciences "frequently found in libraries where readers are not allowed access to the shelves. In it the books are arranged in order of accession, and numbered from one upwards. Thus, number five may be a treatise on botany, number six may be Ruskin's Ant of England, and number seven a book on coal mining. Of course, it is quite obvious that this classification is adapted merely for staff purposes, and particularly to enable certain numbers, which may have been selected from the catalogue, to be readily found by a boy assistant possessing very little knowledge, or to give a rough idea for statistical report of the nature of the books read. Close classification on the shelves has not often been adopted in Britain save in the case of a few reference libraries, and where the decimal system of Mr. Dewey has been applied. The reason, as explained above, is because where the public is excluded there is no absolute need for more than a numerical finding arrangement. It is the purpose of this paper to describe a simple and elastic scheme capable of being applied to reference and lending libraries which are open to public examination. This scheme is neither scientific nor rigid, being simply a framework of suggestions especially intended for small public libraries, which anyone can elaborate or simplify at pleasure. The main features lie in its adaptability for public as against staff use, and the absence of a

\footnotetext{
' Read before the Annual Meeting of the Library Association, Belfact, September, 1894
} 
place or shelf notation for catalogue purposes. It is not possible by any classification scheme to supersede the catalogue, but where a reasonably close classification and public access go hand in hand, a considerable amount of purely descriptive cataloguing may easily be dispensed with. On the other hand, by freeing the catalogue from the congestions which arise on account of elaborate descriptive entries, room is made for various valuable additional features, among which may be named the important possibility of making the catalogue an index of the contents of the library, as well as a mere inventory of the books. This is a point which deserves careful consideration, as it is no more possible to make a shelf classification show the literature possessed by the library on any given subject, than it is possible, without enormous expense, to make a catalogue so descriptive as the actual books themselves. The classification which is proposed in this paper is designed to meet the needs of readers rather than librarians, consequently it is practical and straightforward rather than theoretical. The first requirement sought to be met was that the reader should be able to find together all the complete books on any concrete subject, and that a certain amount of relationship should be shown in the arrangement of the main classes. Thus, all the books on India in its historical and geographical aspects would be placed together, while the subject of India itself forms part of the main class, "History, Travel, and Topography," and that is in close proximity to "Biography." Therefore, the history of any country and the lives of the individuals who made it are capable of being examined side by side. In actual practice it will be found best to make the subdivision of a main class the unit for arrangement and to adopt for it the alphabetical rather than the scientific order. For example, the subject Botany may be arranged in an alphabet of authors' names on the shelves, instead of in groups of subordinate classes, except in large collections, where general works should precede the authors who treat only on a part of the subject, and large groups may exist requiring special treatment. The reasons for this are that the order is more easily maintained, insertions are easier to make, and readers will find it quicker to understand and get what they want. But the scheme as set out on the accompanying table is so elastic and uncomplicated by symbols that sub-division to any extent can be carried out, if the quantity of literature or local circumstances demand it, without in any degree affecting the catalogue. 
Having said so much by way of general explanation, we may proceed to describe the method of applying the scheme to the books of a library which is open to the public. When a new book is received and its class is ascertained, the class letter and number are written behind the title page, or on any other convenient part. In addition, it receives the first blank accession number. The class number enables the assistant to find out exactly to what sub-division of a main class the book belongs, and to locate it there in its alphabetical order. The accession number and class letter are used in the catalogue and for all registration purposes, in connection with a location book containing a complete sequence of accession numbers against which are written the shelf numbers of the books represented. The artual shelves themselves are numbered permanently from one upwards, and books placed on them have the shelf number carried on to their labels. As a "finding" arrangement, it therefore enables books to be procured without delay, either by their authors and titles, or numbers ; in the former case, by going direct to the shelves, and in the latter, by consulting the location book. It is assumed, of course, that the book-cases are properly marked with class and subject labels. It will thus be seen that the accession number printed in the catalogue is not a direct reference to the place of the book in a numerical or other sequence, but simply a guide to an intermediate list in which the exact location is given. The subject of the book itself, in the case of non-fictional and non-poetical works, is the true location. Thus, a person wishing to look at Roscoe's Chemistry, would find it under $\mathrm{R}$ among the general books on chemistry. And here it may be desirable to point out that, even if the alphabetical order is disturbed, the fact remains that the particular book is still confined to one shelf and can very readily be found. Again, in cases where it may be desirable to change the position of a single book or a group of books, nothing more is necessary than to change the shelf numbers on the book labels and in the location book. This does not, in the slightest degree, affect the catalogue. The use of the accession number in the catalogue, instead of class or position numbers, is also of considerable advantage from the readers' point of view, as it enables them to dispense with the bewildering hieroglyphics which make certain American catalogues, compiled on the Dewey or Dewey-Cutter plan, look like cunning cryptograms. For example, according to the A.L.A. model catalogue, if a reader calls for Green's Making 
of England, in a Dewey classified library which uses Cutter's alphabet table as well, he has to write or ask for $94^{\circ}$. I G82 m; or, according to Cutter's Expansive Classification, for $F_{45}{ }^{3} \cdot G 82 \mathrm{~m}$. Fancy charging books by symbols like these ! By the classification here proposed, it would not matter how many symbols were used by the staff, the charging would be done by a simple number like B $649 \mathrm{I}$, and this would also be the readers' short form of demand.

It only remains to make a few explanatory notes on the scheme now submitted. As will be seen from the subjoined table, it consists of eleven main classes, which are divided into divisions, each numbered independently in its own class, and these are capable of being broken up into sub-divisions to almost any extent. Every class, division and sub-division is to be regarded as general, and to make use of the letter or number prefixed to it. Thus C will represent general biography, and B general works on history and travel. In both cases the order would be alphabetical by authors' names, and all through the scheme the alphabet would be the standard for arrangement in classes, divisions, or sub-divisions. To show exactly what is meant, we shall tabulate a portion of class $B$.

B. History, Travel, Topography. General works in author alphabet.

B a. Universal History. I, 2, 3, 4, \&c., if needful.

B b. Dictionaries.

B c. Chronology.

B d. Archæology, general. I, Prehistoric remains, 2, Numismatics, \&c.

B e. Geographical dictionaries, gazetteers, \&c.

B f. Atlases, charts, \&c.

B 1. Europe, general. I, History. 2, Topography.

B I a. British Islands, general. I, History. 2, Topography.

B I b. England, general. I, History. 2, Topography.

B I c. Scotland, general. I, History. 2, Topography.

$B$ I d. Ireland. I, 2.

B I e. Wales, Islands. I, 2.

B If. France, general. I, History. 2, Topography.

B 2. Asia, general. I, History. 2, Geography.

B 2 a. India.

$\mathrm{B} 2 \mathrm{~b}$. China.

B 3. Africa, general. 
The sub-divisions work out to almost any extent by the alternation of numbers and alphabet; and English Topography, for example, could be marked as follows :-
B I b 2 a. Middlesex. Alphabet of general works.
B I b 2 a I. " $\quad$ London, general.
B I b 2 a I a. "
B I b 2 a I b. "
B I b 2 a I c. ,
"Clerkenwell I, 2, 3, 4, \&c.
" Chelsea 1, 2, 3, 4.
" City I, 2, 3, 4, \&c.

Each of these sub-divisions can be sub-divided within themselves by means of the numbers to an endless extent, and, however elaborate the class notation may be, the catalogue and charging number will always remain the simple accession one.

No effort has been made to work out the annexed table, as that is a labour which must be undertaken by each librarian according to his lights. All we have attempted is to furnish a system which frees classification from the complications arising out of the endeavour to conjoin it with location and finding, and to set forth a simple plan whereby the book wealth of a popular library can be displayed on open shelves in as close a relative order as it is possible or desirable.

\section{CLASSIFICATION TABLE.}

1. Reltgton and Philosophy :-

I. Bible. a-Texts. b-Commentaries. c-History. d-Aids.

2. Church. a-History. b-Law. c-Liturgy. dRituals, by sects.

3. ThвогоGy. a-Natural Theology. b-Christianity (sermons arranged by authors). c-Non-Christian Systems. d-Mythology. e-Popular beliefs.

4. Philosopry. a-Schools. b-Mental Science. c-Logic. d-Moral Science.

B. Blatory, Travel, and Tupography :-

Universal History and Geography (a). b-Dictionaries. c-Chronology. d-Archzology (including numismatics). e-Gazetteers. f-Atlases, charts. 
National History and Topography. By countries, subdivided as required : I-Europe : (England: London). 2-Asia. 3-Africa. 4-America. 5-Australasia. 6-Polar Regions.

C. Blography :-

Dictionarirs and Greneral Collections. a-Peerages. b-Army. c-Clergy. d-Law, and other lists. eDignities. f-Heraldry. g-Genealogy, and Family History.

I. Classes, including criticism. a-Actors. b-Artists. c-Authors. d-Clergy and Religious. e-Engineers. f-Inventors. g-Legal. h-Monarchs. i-Philosophers. j-Philanthropists. $\mathrm{k}$-Scientists. l-Statesmen. m-Travellers.

D. Sootal Botenco :-

I. Society. a-Manners and Customs. b-Folk-lore. c-Marriage. d-Women. e-Pauperism. f-Crime. g-Socialism, \&c.

2. Government and Politics. a-Public Documents. b-Statutes, Administration by Departments, as : cArmy. d-Navy. e-Civil Service, \&c.

3. LAw. International, English, Colonial, Foreign. Special, as patent, commercial, landlord and tenant, \&c., as required.

4. Political Economy. Taxation, Free Trade, Capital and Labour, Land, Rent, Statistics.

5. Education. Universities, Schools, Kindergarten, Manual, Methods, Blind and Deaf.

6. Сoмmerce. Banking, Insurance, Money, Communications, Railways, Post Office.

Z. Balence :-

I. Biology. Evolution, Methods, Anatomy, Physiology, Microscopy.

2. Zoology. Vertebratrs: Man, Mammals, Birds, Reptiles, Fishes. Invertebrates: Molluscs, Insects, Lowest forms.

3. Botany. British, with Local floras following. Foreign. Special orders.

4. Grolocy. Palzontology, Mineralogy and Crystallography. 
5. Chemistry. Organic, Inorganic, Special.

6. Physiography. Physical Geography, Meteorology, Natural Phenomena.

7. Astronomy. Histories, Descriptive, Telescopy, Nautical.

8. Physics. Heat, Light, Electricity, Sound, Mechanics, Optics, \&c.

9. Mathematics. Arithmetic, Book-keeping, Algebra, Geometry, Surveying, Weights and Measures.

F. Fine and Reoreative $\Delta$ rts :-

I. Architecture.

2. Painting. Drawing, Perspective, Artistic Anatomy.

3. Sculpture and Carving.

4. Decoration. Ornament, Minor Arts.

5. Engraving. Photography, Writing, Shorthand.

6. Music. History, Theory, Practice.

7. Amusements. Boating and Yachting, Cricket, Football, Cycling, Athletics, Indoor games, \&c.

8. Sports. Hunting, Racing, Shooting, Angling, \&c.

G. Usefal Arte :-

1. Enginefring. Steam, Naval, Military, Civil, Mining, Railway, Electrical.

2. Building and Mechanical Arts. Workshop practice. Trades as represented.

3. Manufactures. Cotton, Silk, Wool, Linen, Leather Book-Paper, Printing, Binding.

4. Agriculture and Gardening.

5. Sba and Navigation. Fisheries, Sea-marks.

6. Henlth and Medicike. Hygiene, Water, Cremation. Medicine, Surgery, Materia Medica, Physical Training.

7. Housenold Arts. Domestic Economy, Cookery, Needlework.

H. Inguage and Literatare:-

1. Philology. Languages alphabetically.

2. Litgrary History.

3. Bibliography.

4. Libraries.

J. Pootry and the Drama :-

1. POETry. Anthologies. Poets alphabetically.

2. Drama. Stage History. Dramatists alphabetically. 
K. Ftotion :-

I. Collections. Author alphabet, and anonyma.

2. Juvenile.

I. General Works :-

I. Encyclopedias. Directories.

2. Miscellanizs. Sketches. Essays. Anecdotes. Recitations. Proverbs.

3. Collected Works.

4. Periodicals not in other classes.

J. Henty Quinn.

JAMES D. BRown.

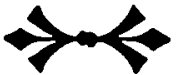

